\title{
KOCHI UNIVERSITY OF TECHNOLOGY
}

\section{Educational expansion and the role of education in ex- penditure inequality in Indonesia since the 1997 financial crisis}

Takahiro Akita

Rikkyo University

14th December, 2015

School of Economics and Management

Research Center for Social Design Engineering

Kochi University of Technology

KUT-SDE working papers are preliminary research documents published by the School of Economics and Management jointly with the Research Center for Social Design Engineering at Kochi University of Technology. To facilitate prompt distribution, they have not been formally reviewed and edited. They are circulated in order to stimulate discussion and critical comment and may be revised. The views and interpretations expressed in these papers are those of the author(s). It is expected that most working papers will be published in some other form. 


\title{
Educational Expansion and the Role of Education in Expenditure Inequality in Indonesia since the 1997 Financial Crisis*
}

\author{
Takahiro Akita \\ College of Business \\ Rikkyo University \\ 3-34-1 Nishi-Ikebukuro, Toshima-ku \\ Tokyo 171-8501, Japan \\ e-mail: akita@ rikkyo.ac.jp
}

\begin{abstract}
Based on the National Socio-Economic Survey (Susenas) from 1997 to 2011, this study examines the role of education in expenditure inequality in Indonesia under educational expansion since the 1997 financial crisis. This is achieved using the three decomposition methods: the Blinder-Oaxaca decomposition; the decomposition of the Gini coefficient; and the hierarchical decomposition of the Theil index. The expansion of education, particularly basic education in rural areas, appears to have not only lowered educational disparity between the urban and rural sectors but also educational inequality within the rural sector. Due in large part to the declining educational disparity between the urban and rural sectors, the urban-rural expenditure disparity has narrowed since the mid-2000s. On the other hand, the expansion of higher education in urban areas appears to have played an important role in the recent rise in overall expenditure inequality by raising not only disparity between educational groups but also inequality within the tertiary education group. Basic education policies would still serve as an effective means to mitigate expenditure inequality, as they could reduce not only educational gap between the urban and rural sectors but also educational inequality within the rural sector by raising general educational levels. Since the expansion of higher education in urban areas seems to be one of the main factors of the recent rise in overall expenditure inequality, higher education policies would also be crucial.
\end{abstract}

Key words: educational expansion; expenditure inequality; decomposition of education Gini; hierarchical decomposition of Theil index; Indonesia

\footnotetext{
* We are grateful to the Japan Society for the Promotion of Science for its financial support (Grant-in-Aid for Scientific Research No.15K03458 and 15K03473). We would also like to thank anonymous reviewers for their helpful comments and Heryanah for obtaining the necessary data for our analysis.
} 


\section{Introduction}

Indonesia has made considerable progress in education since the 1970s. This is mainly due to the implementation of major policies and programs, such as constructing primary schools throughout the country under the Presidential Instruction Primary School program (Inpres Sekolah Dasar) in the 1970s, making six years of primary education compulsory in 1984, extending compulsory education to nine years in 1994, decentralizing managerial and financial responsibilities for public education from the central government to district (Kabupaten/Kota) or provincial governments in $2001,{ }^{1}$ and allocating at least $20 \%$ of national and local government budgets to education in 2003 (Jones and Hagul, 2001; Kristiansen and Pratikno, 2006; Suharti, 2013). In line with the Inpres Sekolah Dasar program, the number of primary schools has increased substantially from 65,000 to 139,000 over the period 1974-1984. By the mid-1980s, Indonesia had achieved universal enrollment of primary education; gross enrolment rate (GER) in primary school has been around $110 \%$ since the late 1980s (Jones and Hagul, 2001; Suharti, 2013). ${ }^{2}$ However, Indonesia has not achieved universal enrolment of junior secondary education yet since the GER in junior secondary school was still around $80 \%$ in 2010, even though the government had extended compulsory basic education to nine years in 1994 (Suharti, 2013).

With notable improvements in basic education across the country, the mean number of years of schooling among the population aged 15 years or over has increased steadily. Over the period 1990-2010, it rose from 6 years to 8 years. This suggests that at least one third of the population would have completed the second level of junior secondary school by 2010. However, there are differences in mean years of education between urban and rural areas, between gender, between types of jobs, and among age groups. In 2010, about $20 \%$ of the population had no education or not completed primary school, and more than two-thirds of them were located in rural areas. On the other hand, more than four-fifths of the population with tertiary education are located in urban areas. The ratio between the urban and rural sectors in mean years of education is still high at around 1.5.

\footnotetext{
1 Two decentralization laws, i.e., Law 22 on Regional Administration and Law 25 on the Fiscal Balance between the Central and the Regional Governments, were enacted in 1999 and implemented in 2001.

2 Though Indonesia has not achieved universal completion of primary education, it has shifted its attention to junior secondary education since the mid-1990s (Jones and Hagul, 2001; Suryadarma and Jones, 2013). According to Suharti (2013), about $80 \%$ of pupils entering primary school actually graduated in academic year $2007 / 08$ and $66 \%$ of them continued to junior secondary education.
} 
Education is thought to be a major determinant of wage income, and a positive relationship is likely to exist between educational inequality and the distribution of income. Whether the expansion of education, which has occurred over the last decades, has narrowed or widened educational inequality is thus of policy relevance in Indonesia. There have been a number of studies that have examined the nexus among the level of educational attainment, educational inequality and the distribution of income. ${ }^{3}$ According to Ram (1990), who investigated the dynamic relationship between the level and inequality of educational attainment using a cross-country dataset of about 100 countries, the relationship is inverted U-shaped, i.e., educational inequality first increases, reaches the peak and then declines with educational expansion. Ram also argued that educational inequality may decline monotonically with educational expansion for less-developed countries which have already reached a certain level of educational attainment and have adopted free and universal primary education as a high-priority goal. Indonesia seems to be among those countries.

The main objective of this study is to examine the role of education in expenditure inequality in Indonesia under educational expansion since the 1997 financial crisis. ${ }^{4}$ This is achieved based on monthly household expenditure data from the National Socio-Economic Survey (Susenas) from 1997 to 2011 using three decomposition methods: the Blinder-Oaxaca decomposition; the decomposition of the Gini coefficient; and the hierarchical decomposition of the Theil index. This study uses expenditure data rather than income data for the following reasons. First, Susenas primarily collects expenditure data, which are more reliable than income data since households in higher income categories tend to underreport their incomes. Second, household expenditure is better than household income as an indicator of household permanent income, since it does not fluctuate as much as household income. Third, the welfare level of a household is better indicated by its current expenditure than current income. It should be noted, however, that since higher-income households tend to save a larger proportion of their incomes, expenditure inequality is generally smaller than income inequality.

This study uses the Theil index $T$ to measure inequality in per capita expenditure

\footnotetext{
3 See, for example, Knight and Sabot (1983), Ram (1989), Ram (1990), Park (1996), Chu (2000), Lin (2006).

${ }^{4}$ In this study, educational expansion implies an increase in the proportion of households whose heads have completed at least secondary education, whether it is led by government policies or not, while the expansion of higher education means an increase in the proportion of households with tertiary education.
} 
(hereafter, expenditure inequality). However, to measure inequality in the number of years of education (hereafter, educational inequality), the Gini coefficient is used, since a household whose head has no education is given 0 year of education and thus it is not possible to calculate the Theil index $T$. These two indices both satisfy desirable properties as a measure of inequality, such as anonymity, income homogeneity, population homogeneity and the Pigue-Dalton transfer principle (Anand, 1983). Furthermore, the Theil index $T$ is additively decomposable by population subgroups in the sense that total inequality is expressed as the sum of the within- and between-group inequality components (Bourguignon, 1979; Shorrocks, 1980).

Educational and expenditure inequalities are analyzed in an urban-rural dual framework because urban-rural disparity is one of the major determinants of expenditure inequality (Eastwood and Lipton, 2004; Shorrocks and Wan, 2005; Kanbur and Zhuang, 2013), and the difference in educational attainment levels is thought to play an important role in the urban-rural expenditure disparity. There are also notable differences between the urban and rural sectors in the structure of educational attainment levels and the magnitude of expenditure inequality. In this study, we first examine the dynamic relationship between the level and inequality of educational attainment in an urban-rural dual setting by the decomposition of the Gini coefficient. Next, we investigate the contribution of differences in educational endowments to the urban-rural expenditure disparity using the Blinder-Oaxaca decomposition method. Finally, using the hierarchical Theil decomposition method developed by Akita and Miyata (2013), we analyze the role of education in expenditure inequality after removing the effect of urban-rural differences in educational endowments on expenditure inequality.

A large number of studies have been conducted to analyze expenditure inequality in Indonesia based on Susenas data. ${ }^{5}$ Among these studies, Akita and Miyata (2008), Akita and Miyata (2013) and Hayashi, Kataoka and Akita (2014) examined the role of education in expenditure inequality in Indonesia. Akita and Miyata (2008) used monthly household expenditure data from the 1996, 1999 and 2002 Susenas to investigate the evolution of expenditure inequality associated with urbanization and educational expansion. According to them, widening inequality among urban households with higher levels of education,

\footnotetext{
${ }^{5}$ See, for example, Hughes and Islam (1981), Islam and Khan (1986), Asra (1989), Akita and Lukman (1999), Akita, Lukman and Yamada (1999), Asra (2000), Akita and Miyata (2008), Akita and Miyata (2013), Sagala, Akita and Yusuf (2014), and Hayashi, Kataoka and Akita (2014).
} 
together with urbanization and educational expansion, appears to have contributed prominently to a rise in overall inequality over the period 1996-2002. Hayashi, Kataoka and Akita (2014) used monthly household expenditure data from the panel Susenas to analyze the role of education in expenditure inequality from spatial perspectives over the period 2008-2010. Using several decomposition methods, including the Blinder-Oaxaca method and the decomposition method of the Theil indices, they found that differences in educational attainment levels appear to have played an important role in expenditure inequality within urban areas and between urban and rural areas.

Our study differs from these studies. First, it uses Susenas data over the period from 1997 to 2011 and thus is able to analyze the evolution of expenditure inequality under educational expansion from a longer-term perspective. Second, prior to an analysis of the role of education in expenditure inequality, it conducts a Gini decomposition analysis to investigate the dynamic relationship between the level and inequality of educational attainment in an urban-rural dual framework. Third, our study employs Susenas data for 15 years from 1997 to 2011 to conduct a Blinder-Oaxaca decomposition analysis; thus, it differs from Hayashi, Kataoka and Akita (2014), in which the panel Susenas for 2008-2010 was used. Fourth, it performs a hierarchical Theil decomposition analysis to examine the role of education in expenditure inequality and compares its result with that of a non-hierarchical Theil decomposition analysis which was proposed by Tang and Petrie (2009).

\section{Method and the Data}

\subsection{Method}

\subsubsection{Blinder-Oaxaca Decomposition}

To analyze the extent to which educational endowments explain the gap between the urban and rural sectors in mean per capita expenditure, we perform a Blinder-Oaxaca decomposition analysis (Blinder, 1973; Oaxaca, 1973). We let $y_{k}, \boldsymbol{X}_{k}, \boldsymbol{\beta}_{k}$, and $e_{k}$ be, respectively, the natural log of per capita expenditure, a vector of explanatory variables, a vector of coefficients associated with $\boldsymbol{X}_{k}$, and the error term. Consider the linear regression model for the urban and rural sectors,

$$
y_{k}=\boldsymbol{X}_{k}{ }^{\prime} \boldsymbol{\beta}_{k}+e_{k} \quad E\left(e_{k}\right)=0 \quad k=U, R .
$$


If we let $\hat{\boldsymbol{\beta}}_{k}, \hat{\boldsymbol{\beta}}^{*}$ and $\overline{\boldsymbol{X}}_{k}$ be, respectively, a vector of the least-squares estimates for $\boldsymbol{\beta}_{k}$ obtained separately from the urban and rural samples $(k=U, R)$, a vector of the least-squares estimates of the coefficients obtained from the pooled sample of urban and rural households, and the estimate for $E\left(\boldsymbol{X}_{k}\right)$, then the estimated urban-rural difference in mean per capita expenditure is given by:

$$
\hat{D}=\bar{y}_{U}-\bar{y}_{R}=\left(\overline{\boldsymbol{X}}_{U}-\overline{\boldsymbol{X}}_{R}\right)^{\prime} \hat{\boldsymbol{\beta}}^{*}+\left(\overline{\boldsymbol{X}}_{U}{ }^{\prime}\left(\hat{\boldsymbol{\beta}}_{U}-\hat{\boldsymbol{\beta}}^{*}\right)+\overline{\boldsymbol{X}}_{R}{ }^{\prime}\left(\hat{\boldsymbol{\beta}}^{*}-\hat{\boldsymbol{\beta}}_{R}\right)\right) .
$$

This is the twofold decomposition suggested by Newmark (1988). The first term in equation (1) is the part that is explained by urban-rural differences in the explanatory variables (endowments effect), while the second term is the unexplained part.

In the regression model, we include, as explanatory variables, years of education, age, age squared, household size, and gender. The number of years of education for the head of a household is determined according to the following: no schooling (0 year); incomplete primary school (3 years); general and Islamic primary schools (6 years); general and Islamic junior high schools (9 years); general, Islamic and vocational senior high schools (12 years); diploma I and II (13 years); diploma III (15 years); diploma IV (Bachelor's degree) (16 years); and master's or doctor's degree (18 years).

\subsubsection{Decomposition of Education Gini Coefficient by Location (Urban and Rural Sectors)}

To analyze the evolution of educational inequality under the expansion of education, we conduct an inequality decomposition analysis by urban and rural sectors using the Gini coefficient. Unlike the generalized entropy class of inequality measures including the Theil index $T$ discussed below, the Gini coefficient fails to decompose additively into withinand between-sector components since an extra term emerges if the distributions of educational attainment for the urban and rural sectors overlap. Nevertheless, we employ the Gini coefficient to examine the evolution of educational inequality in an urban-rural dual framework, since there is a certain overlap between the urban and rural sectors in the level of educational attainment and, thus, it is interesting to analyze how this overlap evolves with the expansion of education.

Suppose that there are $N$ households in a country, who are classified into the urban and the rural sectors (sectors 1 and 2, respectively), and the educational level of a household is 
measured by the number of years of education completed by its household head. We let $e_{i h}, \mu$ and $N_{i}$. be the number of years of education of household $h$ in sector $i$, the mean number of years of education of all households, and the total number of households in sector $i$. Then, overall inequality in years of education can be measured by the following Gini coefficient:

$$
G=\frac{1}{2 N^{2} \mu} \sum_{i=1}^{2} \sum_{j=1}^{2} \sum_{h=1}^{N_{i}} \sum_{k=1}^{N_{j}}\left|e_{i h}-e_{j k}\right|
$$

This education Gini can be additively decomposed into the within-sector Gini $\left(G_{W S}\right)$, the between-sector Gini $\left(G_{B S}\right)$ and the residual term $\left(G_{R}\right)$ as follows (for details, see Lambert and Aronson, 1993; Dagum, 1997).

$$
G=G_{W S}+G_{B S}+G_{R} .
$$

In this decomposition equation, $G_{W S}$ is a weighted average of the Gini coefficients for the urban and rural sectors, which is defined as

$$
G_{W S}=\sum_{i=1}^{2} p_{i} s_{i} G_{i}
$$

where $p_{i}, s_{i}$, and $G_{i}$ are, respectively, the share of sector $i$ in the total number of households, the share of sector $i$ in the total number of years of education, and the Gini coefficient of sector $i$. On the other hand, $G_{B S}$ is the Gini coefficient that would be obtained if each household in a given sector was given the mean number of years of education for the sector. $G_{B S}$ is, thus, defined as

$$
G_{B S}=\frac{1}{2 N^{2} \mu} \sum_{i=1}^{2} \sum_{j=1}^{2} \sum_{h=1}^{N_{i}} \sum_{k=1}^{N_{j}}\left|\mu_{i}-\mu_{j}\right|=\frac{1}{2 \mu} \sum_{i=1}^{2} \sum_{j=1}^{2} p_{i} p_{j}\left|\mu_{i}-\mu_{j}\right|
$$

where $\mu_{i}$ is the mean number of years of education in sector $i$. Finally, the residual term is given by $G_{R}=G-G_{W S}-G_{B S}$, which is zero if the distributions of years of education for the urban and rural sectors do not overlap; but takes a positive value if they overlap.

\subsubsection{Hierarchical Decomposition of Expenditure Inequality by the Theil Index $T$}

To investigate the roles of education in expenditure inequality in an urban-rural dual framework, we conduct a hierarchical inequality decomposition analysis by location and 
education using the Theil index $T$. In the hierarchical Theil decomposition method advanced by Akita and Miyata (2013), all households are first grouped into the urban and rural sectors; then, households in each of these sectors are classified into the three education groups: the primary, secondary and tertiary education groups (groups 1, 2 and 3, respectively).

We let $y_{i j k}, Y$ and $N_{i j}$ be, respectively, the per capita expenditure of household $k$ in education group $j$ in sector $i$, the total per capita expenditure of all households, and the number of households in education group $j$ in sector $i$. Then overall inequality in per capita expenditure is given by the Theil index $T$ as follows:

$$
T=\sum_{i=1}^{2} \sum_{j=1}^{3} \sum_{k=1}^{N_{i j}}\left(\frac{1}{N}\right) \log \left(\frac{1 / N}{y_{i j k} / Y}\right)
$$

Next we let $Y_{i j}$ and $Y_{i}$ denote, respectively, the total per capita expenditure of households in education group $j$ in sector $i$ and the total per capita expenditure of households in sector $i$. Then, the Theil index $T$ in equation (6) can be decomposed hierarchically into the between-sector inequality component $\left(T_{B S}\right)$, the within-sector between-group inequality component $\left(T_{W S B G}\right)$, and the within-sector within-group inequality component ( $\left.T_{W S W G}\right)$ as follows (see Akita and Miyata, 2013 for more detail):

$$
\begin{aligned}
T & =T_{B S}+\sum_{i=1}^{2}\left(\frac{Y_{i}}{Y}\right) T_{i} \\
& =T_{B S}+\sum_{i=1}^{2}\left(\frac{Y_{i}}{Y}\right) T_{B G i}+\sum_{i=1}^{2} \sum_{j=1}^{3}\left(\frac{Y_{i j}}{Y}\right) T_{i j} \\
& =T_{B S}+T_{W S B G}+T_{W S W G} .
\end{aligned}
$$

where $T_{i}, T_{B G i}$ and $T_{i j}$ are, respectively, inequality within sector $i$, inequality between education groups in sector $i$, and inequality within education group $j$ in sector $i$. Equation (7) presents the hierarchical inequality decomposition equation for location and education.

We should note that the two-stage nested Theil decomposition method, developed by Akita (2003), is similar to equation (7). However, it is based on district-level GDP data rather than household-level data and considers a natural hierarchical structure, i.e., region-province-district, in which each region is composed of a different set of provinces 
and each province consists of a different set of districts. By contrast, in equation (7), the urban and rural sectors have the same set of education groups, i.e., the primary, secondary and tertiary groups.

In the hierarchical decomposition, the order of decomposition can be reversed, i.e., overall inequality can be decomposed hierarchically into the between-group inequality component $\left(T_{B G}\right)$, the within-group between-sector inequality component $\left(T_{W G B S}\right)$, and the within-group within-sector inequality component $\left(T_{W G W S}\right)$ as follows:

$$
T=T_{B G}+T_{W G B S}+T_{W G W S}
$$

We should note that $T_{W G W S}$ in equation (8) is the same as $T_{W S W G}$ in equation (7), since we have

$$
T_{W S W G}=\sum_{i=1}^{2} \sum_{j=1}^{3}\left(\frac{Y_{i j}}{Y}\right) T_{i j}=\sum_{j=1}^{3} \sum_{i=1}^{2}\left(\frac{Y_{i j}}{Y}\right) T_{i j}=T_{W G W S} .
$$

In the hierarchical inequality decomposition method, therefore, the order of decomposition matters. In order to cope with this problem, Tang and Petrie (2009) proposed an alternative multivariate decomposition framework, i.e., the non-hierarchical decomposition method, in which the Theil index is decomposed non-hierarchically, i.e., simultaneously with respect to some nominal scaled variables such as location, education, gender, ethnicity and age. In the context of inequality decomposition by location and education, the non-hierarchical decomposition equation is given by:

$$
T=T_{B S}+T_{B G}+T_{I S G}+T_{W S W G}
$$

where $T_{I S G}$ is the sector-group interaction term. Since we have $T_{W S B G}=T_{B G}+T_{I S G}$ from equations (7) and (9), the interaction term is obtained by $T_{I S G}=T_{W S B G}-T_{B G}$. We should note, however, that the non-hierarchical decomposition method is unable to examine the difference in the structure of educational attainment between the urban and rural sectors, even though it can suggest, based on an interaction term, the significance of the difference in educational endowments between them. In contrast, the hierarchical decomposition method is able to analyze the difference in the structure of educational attainment by performing a one-stage decomposition analysis by education for each sector. 


\subsection{The Data}

This study uses monthly household expenditure data from the National Socio-Economic Survey (Susenas) from 1997 to 2011, which has been conducted by the Central Bureau of Statistics (CBS). ${ }^{6}$ Table 1 presents the sample size of Susenas, the distribution of households across three educational groups in each sector and the shares of the urban and rural sectors for selected years, where the distribution of households and the urban and rural shares are based on the estimated number of households obtained using sampling weights, not on the number of sampled households. It should be noted that the primary education group includes households whose heads have either no education, incomplete primary education or primary education. The secondary group consists of households whose heads completed junior high school or senior high school, whereas the tertiary group includes households whose heads have completed one, two, three-year junior college (Diploma 1, 2, 3), four-year university/college (Sarjana 1/Diploma 1), master's program (Sarjana 2) or doctoral program (Sarjana 3).

\section{Table 1}

The sample size has increased gradually; in 2011, it included 268,522 households, of which 113,397 and 155,125 households are in urban and rural areas, respectively. However, the sample accounts for a constant proportion of the population of households at around $0.4-0.5 \%$. Over the study period, urbanization has proceeded quite rapidly; in 1997, the urban share was around $36 \%$, but rose to almost $50 \%$ in 2011. In the urban sector, while the primary education group has lowered its share from $44 \%$ to $40 \%$, the tertiary group has raised its share from $11 \%$ to $14 \%$. On the other hand, in the rural sector, the primary sector has lowered its share substantially by 11 percentage points, though it still occupies more than two thirds of rural households. By contrast, the secondary sector has increased its share prominently; in 2011, the share amounted to $28 \%$. The share of the tertiary sector has increased also, but slightly.

\section{Empirical Results}

It is instructive to start with an analysis of the levels and trends of expenditure inequality

\footnotetext{
6 In 2011, Susenas was conducted quarterly; thus for 2011, we used the Susenas dataset that was constructed by merging four quarterly Susenas by CBS. Since there might have been seasonal variations in expenditure inequality across quarters, some care should be taken in interpreting the result.
} 
for the period 1997-2011. Figure 1 presents overall expenditure inequality as measured by the Theil T. It also shows urban and rural inequalities and the contribution of the between-sector inequality to overall inequality. Before 2004, overall inequality was relatively stable at around 0.20-0.25; but it rose sharply to 0.29 in 2005. After it went down to 0.20 in 2007, it increased prominently to 0.32 in 2011. Between 2003 and 2005, the two richest decile groups of households increased their expenditure shares, while the shares of the other groups declined, and the ratio of the expenditure share of the richest $20 \%$ to that of the poorest $20 \%$ (Kuznets 20/20 ratio) rose notably from 4.8 to 6.3. Yusuf, Sumner and Rum (2014) argued that rising domestic rice prices during 2003-2005 after a long stable period would be one of the major causes of the increase in expenditure inequality, as the price hike may have exerted a more detrimental effect on the poor than the rich. Like the period 2003-2005, the Kuznets 20/20 ratio rose sharply from 4.9 to 6.9 between 2007 and 2011. Yusuf, Sumner and Rum (2014) proposed some factors for the recent rise in expenditure inequality. The authors argued that increasingly large fuel subsidies would have raised expenditure inequality, since their impact on incomes is known to have been regressive and thus has had a dis-equalizing effect on expenditures. They also argued that changes in formal labor market regulations, such as rising minimum wages, the strengthening of labor unions, increasing retirement benefits, would have increased inequality, as the changes are likely to have benefited the rich disproportionately more than the poor.

\section{Figure 1}

During the study period, urbanization has proceeded very rapidly; in 1997, the urban sector accounted for $36 \%$ of all households, but its share had been rising gradually and reached 50\% in 2011. Due in large part to this rising urbanization, the levels and trends of overall inequality resemble very closely those of urban inequality, particularly after 2001 when Indonesia recovered fully from the 1997/98 financial crisis and two decentralization laws were implemented. Like other Asian countries, rural inequality has been much smaller than urban inequality (Eastwood and Lipton, 2004); but except in 1999, its rising and declining trends have been very similar to those of urban inequality.

According to a Theil decomposition analysis by urban and rural locations, the contribution of the between-sector inequality to overall inequality has displayed a similar trend pattern to that of overall inequality. However, this pattern discontinued in 2007. 
While the contribution has declined from $19 \%$ to $11 \%$ since 2007 , overall inequality has risen substantially from 0.19 to 0.32 . This implies that a rapid rise in expenditure inequality since 2007 is due largely to an increase in within-sector inequalities, particularly urban inequality. In fact, the between-sector inequality has remained constant at around 0.035 by the Theil $T$ since 2007 , while the within-sector inequality component has risen significantly from 0.16 to 0.29 .

Before examining the roles of education in expenditure inequality, it is instructive to analyze the dynamic relationship between the level and inequality of educational attainment. Over the period 1997-2011, the mean level of educational attainment increased steadily in both urban and rural areas (see Table 2). In 1997, the mean years of education in the urban and rural sectors were, respectively, 8.4 and 5.1 years; but they increased gradually to 9.2 and 6.3 years in 2011 . We should note that the speed of educational expansion has been faster in rural than urban areas; thus the urban-rural ratio in mean years of education declined to 1.46 in 2011 from 1.66. Nonetheless, there is still a noticeable educational disparity between the sectors.

Table 2

Figure 2 presents the result of the decomposition of educational inequality by urban and rural sectors using the Gini coefficient. With the expansion of education, overall educational inequality has declined gradually, from 0.38 to 0.33 by the Gini coefficient. The expansion of education, particularly basic education in rural areas, appears to have not only lowered educational disparity between the urban and rural sectors (from 0.12 to 0.09 by the Gini coefficient) but also educational inequality within the rural sector (from 0.39 to 0.34 by the Gini coefficient). Their combined contribution to overall educational inequality has thus declined from $67 \%$ to $49 \%$. Meanwhile, the contribution of the residual term, which denotes the magnitude of the overlap in the distribution of educational attainment between the urban and rural sectors, has risen significantly from $19 \%$ to $25 \%$. Unlike expenditure inequality, the urban sector has a much smaller educational inequality than the rural sector. However, its educational inequality has remained almost constant at around $0.28-0.30$; thus the difference in educational inequality between the urban and rural sectors has narrowed.

\section{Figure 2}

In order to investigate the extent to which the difference in the level of educational 
attainment explains the urban-rural expenditure disparity, we conducted a Blinder-Oaxaca decomposition analysis. The result for selected years is presented in Table 3. The difference in educational endowments has been the major factor of the urban-rural expenditure disparity. The difference in mean years of education accounts for more than $30 \%$ of the urban-rural disparity. ${ }^{7}$ Particularly, in 2011 , it explains $42 \%$ of the disparity. Thus, reducing the urban-rural gap in educational attainment level would lower the urban-rural expenditure disparity to a certain extent. Since the proportion of rural households whose heads have either no education or incomplete primary education is still very high at $35 \%$ in 2011 , it is imperative to raise the level of educational attainment to at least primary education in rural areas. Given the types and nature of jobs available in rural areas, however, it would not be easy to remove the urban-rural educational gap and it would take time to narrow the gap. Due partly to the difficulty in reducing the urban-rural educational gap, the between-sector expenditure inequality has remained constant since 2007. On the other hand, within-sector inequalities, particularly urban inequality, have played an important role in the rising overall inequality. Therefore, reducing within-sector inequalities, particularly urban inequality, is essential to lower overall expenditure inequality.

\section{Table 3}

According to the result of a non-hierarchical decomposition analysis, ${ }^{8}$ expenditure disparity between educational groups (i.e., between-group component in equation (9)) accounts for around 20-24\% of overall expenditure inequality. ${ }^{9}$ As shown by a large negative sector-group interaction term, however, much of the contribution to overall inequality is due to the educational gap between the urban and rural sectors. This is, in fact, exemplified by the Blinder-Oaxaca decomposition analysis discussed above. Thus, it is essential to analyze the role of education separately for the urban and rural sectors.

Table 4 shows the result of a Theil decomposition analysis by educational group in each of the urban and rural sectors in addition to the result of a Theil decomposition analysis by urban and rural locations, where the contributions are all measured against

\footnotetext{
7 Our result confirms the result of Hayashi, Kataoka and Akita (2014), which states that the difference in educational endowments explains about $36 \%$ of the urban-rural expenditure gap.

8 The result is presented in Table 5.

9 In most other countries, differences in educational attainment account for $20-40 \%$ of overall inequality. See, for example, Glewwe (1986), Tsakloglou (1993), Estudillo (1997), Rao, Banerjee, and Mukhopadhaya, (2003).
} 
overall inequality rather than urban or rural inequality. Major findings from this decomposition analysis are summarized as follows. First, there is a large difference between the urban and rural sectors in the contribution of inequality between educational groups to overall expenditure inequality. In urban areas, expenditure disparity between educational groups is a prominent contributor to overall inequality, by accounting for $10-15 \%$; but it is not in rural areas, by explaining merely 1-2\%. In other words, expenditure inequality due to educational differences is more an urban phenomenon.

\section{Tables 4}

Second, expenditure disparity between educational groups has risen in both urban and rural sectors. Particularly in the urban sector, it has increased its contribution from 10 to $15 \%$ since 2000. Third, in both urban and rural sectors, higher educational groups tend to have a larger within-group inequality. In 2011, the tertiary education group had a very high within-group inequality at 0.30 in the urban sector, which is followed by the secondary education group at 0.24 . Fourth, the contribution of tertiary group's inequality in urban areas was $11 \%$ in 2000 , but increased gradually to $16 \%$ in 2011 . The recent rise in overall expenditure inequality seems to have been due not only to a rise in inequality between educational groups but also an increase in tertiary group's inequality in urban areas. They, together, accounted for more than $30 \%$ in 2011 , compared to $21 \%$ in 2000 . Unless these inequalities are reduced, therefore, overall inequality would not decrease.

Table 5 presents the result of a hierarchical inequality decomposition analysis. The analysis combines, hierarchically, decomposition analyses by educational groups in the urban and rural sectors discussed above with decomposition analysis by urban and rural locations (see equation (7)). The contributions of the between-sector inequality (BS) and the within-sector between-group inequality (WSBG) have exhibited opposite trends since the mid-2000s, i.e., while the contribution of BS has declined, that of WSBG has increased, where the contribution of WSBG is the sum of the contributions of urban and rural sector's between-group inequalities. Due in large part to the declining disparity in educational endowments between the urban and rural sectors, the urban-rural expenditure disparity has narrowed since the mid-2000s. However, at the same time, the expansion of higher education has brought about an increase in expenditure disparity between educational groups in urban areas. This is in spite of the fact that urban sector's educational inequality has remained almost constant over the study period (see Figure 2). The expansion of higher 
education has also raised expenditure disparity between educational groups in rural areas, but its contribution to overall inequality has been very small, as discussed above.

\section{Table 5}

The expansion of higher education in urban areas appears to have played an important role in the recent rise in overall expenditure inequality by raising not only disparity between educational groups but also inequality within the tertiary education group. The tertiary education sector started to grow very rapidly from the 1980s, with the labor market requiring more formal professional qualifications and demanding a more skilled workforce (Hill and Wie, 2013). In 2001, the GER in tertiary education was 14.4\%; but by 2010 it increased to 23.1\% (Hill and Wie, 2013). Based on the 2011 Susenas, Table 6 presents the distribution of households according to occupation in each of the three educational groups. In the tertiary education group, about $8.5 \%$ of urban households are engaged in the information/communication and finance/real estate sectors. This share is much larger than the shares in the primary and secondary education groups $(0.3 \%$ and $2.4 \%$, respectively). These two sectors have been growing very rapidly; their annual average GDP growth rates, respectively, at $21.1 \%$ and $6.7 \%$ over the period $2000-11$, are much larger than the country's growth rate of $5.3 \%$. Though not as rapid as the information/communication and finance/real estate sectors, the education, health and government services sectors have also grown more rapidly than the country as a whole, and these services sectors have very large shares of households in the tertiary education group as compared to the primary and secondary groups. Due to growing demands for technical, managerial and professional skills required for these services sectors, households in the sectors seem to have had increasingly high wages and salaries as they have much higher mean per capita expenditures than those in other sectors in 2011. Besides the factors suggested by Yusuf, Sumner and Rum (2014), such as increasingly large fuel subsidies and changes in formal labor market regulations, these observations are indicative of the growing inequality within the tertiary education group over the last several years.

\section{Table 6}

The tertiary education group comprises three subgroups of households with respect to educational attainment levels: one, two or three-year junior college (subgroup1: Diploma 1, 2 or 3); four-year university/college (subgroup 2: Sarjana 1/Diploma 4); and master's or doctoral program (subgroup 3: Sarjana 2 or 3). Thus, we are able to further decompose its 
within-group inequality into inequalities within and between these three subgroups. Table 7 presents the result of this inequality decomposition in urban areas for 2000 and 2011. One of the major findings is that variations in mean per capita expenditure among the three subgroups are very small in urban areas. In 2011, the ratio between subgroups 3 and 1 in mean per capita expenditure was 1.5, while the ratio between subgroups 2 and 1 was 1.1. This implies that tertiary group's inequality in urban areas is due largely to inequalities within its subgroups. Particularly in 2011, subgroup 1 (Diploma 1, 2 or 3) had a very large inequality at 0.4 , a significant increase from 0.23 in 2000 . This seems to have substantially contributed to a recent rise in expenditure inequality within the tertiary education group. Large inequalities within educational subgroups indicate that there are wide variations in quality at the same educational level.

\section{Table 7}

\section{Conclusion}

Based on the National Socio-Economic Survey (Susenas) from 1997 to 2011, this study has examined the role of education in expenditure inequality in Indonesia under educational expansion since the 1997 financial crisis. This has been achieved using the three decomposition methods: the Blinder-Oaxaca decomposition; the decomposition of the Gini coefficient; and the hierarchical decomposition of the Theil index.

The main findings are summarized as follows. First, due to rising urbanization, the levels and trends of overall expenditure inequality resemble very closely those of urban inequality. In accordance with the Theil decomposition analysis by urban and rural locations, a rapid rise in overall expenditure inequality since 2007 is due largely to an increase in urban inequality. Second, the mean years of education have increased steadily in both urban and rural areas: from 8.4 to 9.2 years and 5.1 to 6.3 years, respectively over the study period. Meanwhile, overall educational inequality, as measured by the Gini coefficient, has declined. The expansion of education, particularly basic education in rural areas, appears to have not only lowered educational disparity between the urban and rural sectors but also educational inequality within the rural sector. Third, according to the Blinder-Oaxaca decomposition analysis, the difference in mean years of education has been the major factor for the urban-rural expenditure disparity by accounting for more than $30 \%$ of the disparity. Due in large part to the declining educational disparity between the 
urban and rural sectors, the urban-rural expenditure disparity has narrowed since the mid-2000s.

Fourth, expenditure disparity between educational groups in the urban sector is a prominent contributor to overall expenditure inequality, and its contribution has increased since 2000. In both urban and rural sectors, the tertiary education group has the largest within-group inequality, which is followed by the secondary and primary education groups, and its contribution to overall expenditure inequality has risen gradually. Fifth, the expansion of higher education in urban areas appears to have played an important role in the recent rise in overall expenditure inequality by raising not only disparity between educational groups but also inequality within the tertiary education group.

From these findings, some policy implications can be drawn. First, basic education policies would still serve as an effective means to mitigate expenditure inequality, as they could reduce not only educational gap between the urban and rural sectors but also educational inequality within the rural sector by raising general educational levels. Given the types and nature of jobs available in rural areas, however, it would not be easy to remove the urban-rural educational gap and it would take time to narrow the gap. We should note here that more than $15 \%$ of the population aged 15 years and over have incomplete primary education; thus, it is essential to lower dropout rate at the primary school level. Second, since expenditure disparity between educational groups is a prominent contributor to overall expenditure inequality, the government should further improve the quality of primary and secondary education and thereby raise the gross enrolment rate (GER) in tertiary education, as the GER in 2010 at $23.1 \%$ is still very low as compared to neighboring Asian countries, e.g., Malaysia (40.2\%) and Thailand (45.8\%) (Hill and Wie, 2013).

Third, since the expansion of higher education in urban areas seems to be one of the main factors of the recent rise in overall expenditure inequality, higher education policies would also be crucial. As the economy develops, more specialized jobs requiring different professional skills and knowledge will become increasingly available, and even more people will obtain higher education to meet the demands for these skills and knowledge. In order to alleviate inequality, therefore, the government will need to introduce higher education policies that could reduce inequality among households with a tertiary education. 
We should note in this connection that there are huge variations in quality among tertiary education institutions, including universities, academies, polytechnics and advanced schools (Hill and Wie, 2013). The government should, therefore, implement policies that could raise the general quality level of higher education. Since there seems to have been a growing mismatch between the qualifications of university and college graduates and the needs of employers, the government should also introduce policies that could promote linkages between industry and academia to remove the mismatch.

\section{References}

Akita, T. (2003). Decomposing regional income inequality in China and Indonesia using two-stage nested Theil decomposition method. The Annals of Regional Science, 37(1), $55-77$.

Akita, T., \& Lukman, R.A. (1999). Spatial patterns of expenditure inequalities in Indonesia: 1987, 1990, and 1993. Bulletin of Indonesian Economic Studies, 35, 67-90.

Akita, T., Lukman, R. A., \& Yamada, Y. (1999). Inequality in the distribution of household expenditures in Indonesia: a Theil decomposition analysis. The Developing Economies, 37 (2), 197-221.

Akita, T., \& Miyata, S. (2008). Urbanization, educational expansion, and expenditure inequality in Indonesia in 1996, 1999, and 2002. Journal of the Asia Pacific Economy, 13(2), 147-67.

Akita, T., \& Miyata, S. (2013). The roles of location and education in the distribution of economic well-being in Indonesia: hierarchical and non-hierarchical inequality decomposition analyses. Letters in Spatial and Resource Sciences, 6(3), 137-150.

Anand, S. (1983). Inequality and Poverty in Malaysia: Measurement and Decomposition. New York: Oxford University Press.

Asra, A. (1989). Inequality trends in Indonesia, 1969-1981: A re-examination. Bulletin of Indonesian Economic Studies, 25(2), 100-110.

Asra, A. (2000). Poverty and inequality in Indonesia: estimates, decomposition and key issues. Journal of the Asia and Pacific Economy, 5, 91-111.

Blinder, A.S. (1973). Wage discrimination: Reduced form and structural estimates. Journal of Human Resources, 8(4), 436-55.

Bourguignon, F. (1979). Decomposable income inequality measures. Econometrica, 47(4), 901-20. 
Chu, H. Y. (2000). The impacts of educational expansion and schooling inequality on income distribution. Quarterly Journal of Business and Economics, 39(2), 39-49.

Dagum, C. (1997). A new approach to the decomposition of the Gini income inequality ratio. Empirical Economics, 22, 515-531.

Eastwood, R. \& Lipton, M. (2004). Rural and urban income inequality and poverty: Does convergence between sectors offset divergence within them?. In G. A. Cornia (Ed.) Inequality, Growth, and Poverty in an Era of Liberalization and Globalization. Oxford: Oxford University Press, pp.112-141.

Estudillo, J.P. (1997). Income inequality in the Philippines, 1961-91. The Developing Economies, 35(1), 68-95.

Glewwe, P. (1986). The distribution of income in Sri Lanka in 1969-70 and 1980-81: A decomposition analysis. Journal of Development Economics, 24(2), 255-274.

Hayashi, M., Kataoka, M., \& Akita, T. (2014). Expenditure inequality in Indonesia, 2008-2010: A spatial decomposition analysis and the role of education. Asian Economic Journal, 28(4), 389-411.

Hill, H., \& Wie, T. K. (2013). Indonesian Universities: Rapid growth, major challenges. In D. Suryadarma \& G. W. Jones (Eds.), Education in Indonesia. Singapore: ISEAS Publishing, 160-179.

Hughes, G. A., \& Islam, I. (1981). Inequality in Indonesia: a decomposition analysis. Bulletin of Indonesian Economic Studies, 17(2), 42-71.

Islam, I., \& Khan, H. (1986). Spatial patterns of inequality and poverty in Indonesia. Bulletin of Indonesian Economic Studies, 22(2), 80-102.

Jones, G. W., \& Hagul, P. (2001) Schooling in Indonesia: Crisis-related and Longer-term issues. Bulletin of Indonesian Economic Studies, 37(2), 207-231.

Kanbur, R., \& Zhuang, J. (2013). Urbanization and inequality in Asia. Asian Development Review, 30(1), 131-147.

Knight, J.B., \& Sabot, R.H. (1983). Educational expansion and the Kuznets effect. The American Economic Review, 73(5), 1132-1136.

Kristiansen, S., \& Pratikno. (2006). Decentralizing education in Indonesia. International Journal of Educational Development, 26, 513-531.

Lambert, P. J., \& Aronson, J. R. (1993). Inequality decomposition analysis and the Gini coefficient revisited. The Economic Journal, 103, 1221-1227.

Lin, C. H. A. (2006). Educational expansion, educational inequality, and income inequality: Evidence from Taiwan, 1976-2003. Social Indicators Research, 80, 601-615.

Neumark, D. (1988). Employers' discriminatory behavior and the estimation of wage discrimination. Journal of Human Resources, 23(3), 279-95

Oaxaca, R. (1973). Male-female wage differentials in urban labor markets. International 
Economic Review, 14(3), 693-709.

Park, K. H. (1996). Educational expansion and educational inequality on income distribution. Economics of Education Review, 15(1), 51-58.

Ram, R. (1989). Can educational expansion reduce income inequality in less-developed countries. Economics of Education Review, 8(2), 185-195.

Ram, R. (1990). Educational expansion and schooling inequality: international evidence and some implications. The Review of Economics and Statistics, 72(2), 266-274.

Rao, V. V. B., Banerjee, D.S., \& Mukhopadhaya, P. (2003). Earnings inequality in Singapore. Journal of the Asia Pacific Economy, 8(2), 210-228.

Sagala, P., Akita, T. \& Yusuf, A. A. (2014). Urbanization and expenditure inequality in Indonesia: testing the Kuznets hypothesis with provincial panel data. Letters in Spatial and Resource Sciences, 8(3), 133-147.

Shorrocks, A. (1980). The class of additively decomposable inequality measures. Econometrica, 48(3), 613-25.

Shorrocks, A., \& Wan, G. (2005). Spatial decomposition of inequality. Journal of Economic Geography. 5(1), 59-81.

Suharti. (2013). Trends in education in Indonesia. In D. Suryadarma \& G. W. Jones (Eds.), Education in Indonesia. Singapore: ISEAS Publishing, 15-52.

Suryadarma, D., \& Jones, G. W. (2013). Meeting the education challenge. In D. Suryadarma \& G. W. Jones (Eds.), Education in Indonesia. Singapore: ISEAS Publishing, 1-14.

Tang, K.K., \& Petrie, D. (2009). Non-hierarchical bivariate decomposition of Theil indexes. Economics Bulletin, 29(2), 928-927.

Tsakloglou, P. (1993). Aspects of inequality in Greece: measurement, decomposition and intertemporal change, 1974, 1982. Journal of Development Economics, 40(1), 53-74.

Yusuf, A A., Sumner, A., \& Rum, I. A. (2014), Twenty years of expenditure inequality in Indonesia, 1993-2013. Bulletin of Indonesian Economic Studies, 50(2), 243-254. 


\section{Figure 1}

Expenditure Inequalities by Theil T Index and Contribution of Between Sector Inequality

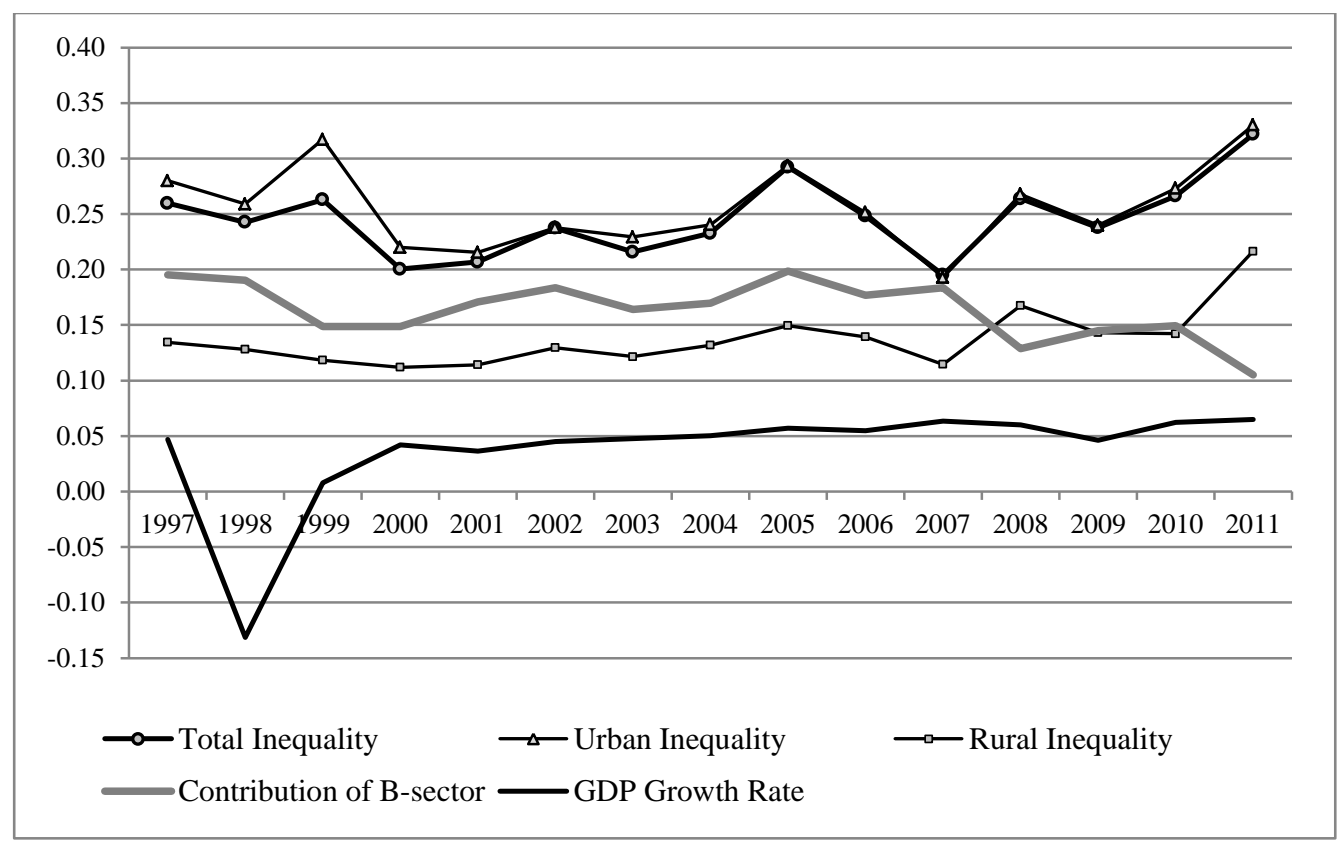

Figure 2

Decomposition of Educational Gini Coefficient by Urban and Rural Sectors

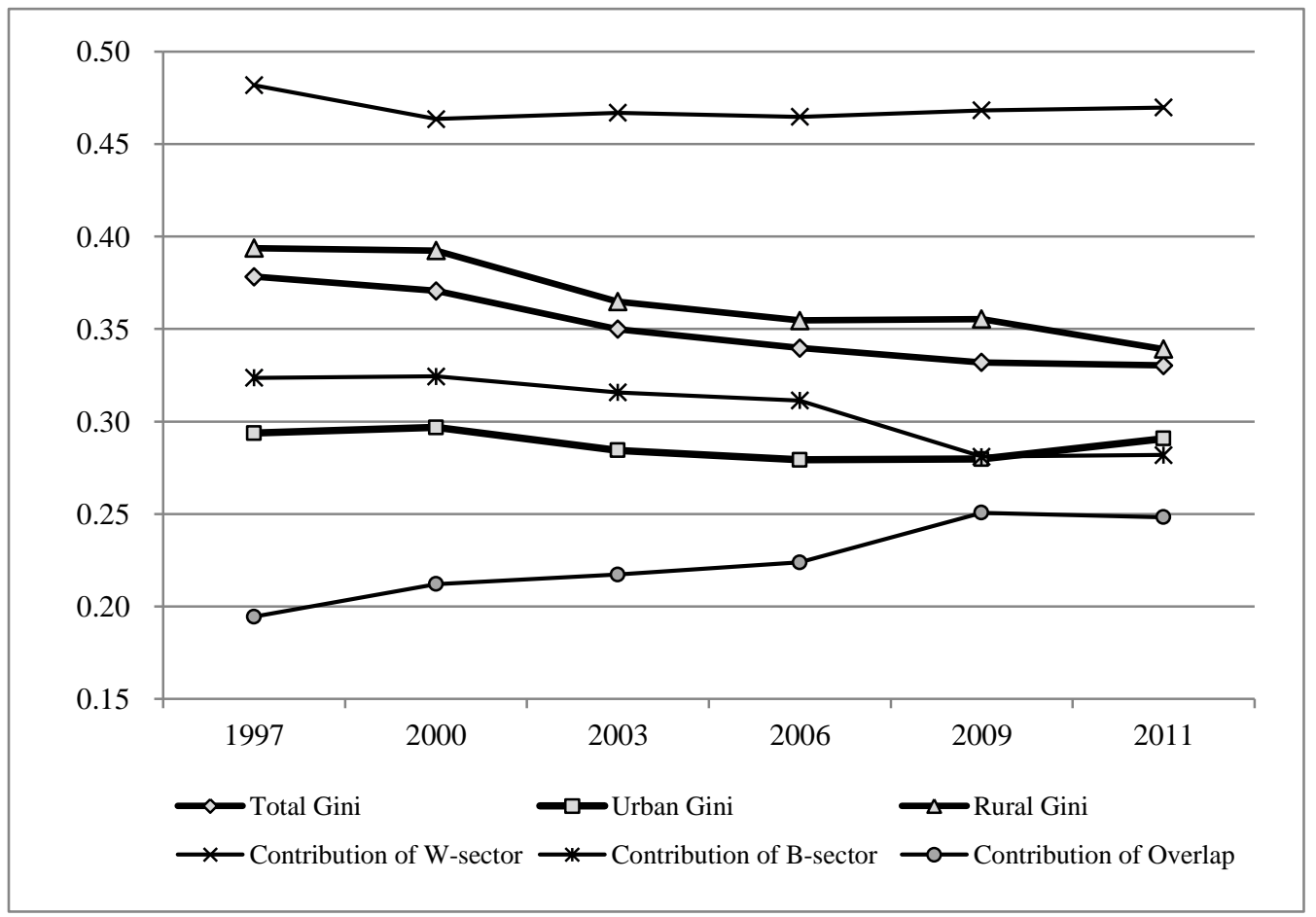




\section{Table 1}

\section{Sample Size and Distribution of Households by Educational Group in Urban and Rural Sectors}

\begin{tabular}{|c|c|c|c|c|c|c|c|c|}
\hline & \multicolumn{4}{|c|}{ Sample Size } & \multicolumn{3}{|c|}{$\begin{array}{c}\text { Distribution of Households across } \\
\text { Educational Groups in Each } \\
\text { Sector }(\%)\end{array}$} & \multirow{2}{*}{$\begin{array}{c}\text { Urban \& } \\
\text { Rural } \\
\text { Shares } \\
(\%)\end{array}$} \\
\hline & Primary & Secondary & Tertiary & Total & Primary & Secondary & Tertiary & \\
\hline \multicolumn{9}{|l|}{1997} \\
\hline Urban & 29,329 & 31,733 & 7,522 & 68,584 & 44.3 & 45.1 & 10.7 & 35.6 \\
\hline Rural & 106,130 & 29,756 & 2,881 & 138,767 & 79.6 & 18.8 & 1.7 & 64.4 \\
\hline Total & 135,459 & 61,489 & 10,403 & 207,351 & 67.0 & 28.1 & 4.9 & 100.0 \\
\hline \multicolumn{9}{|l|}{2000} \\
\hline Urban & 32,053 & 33,708 & 8,168 & 73,929 & 45.3 & 44.2 & 10.5 & 42.2 \\
\hline Rural & 87,015 & 25,879 & 2,500 & 115,394 & 78.4 & 19.8 & 1.8 & 57.8 \\
\hline Total & 119,068 & 59,587 & 10,668 & 189,323 & 64.5 & 30.1 & 5.5 & 100.0 \\
\hline \multicolumn{9}{|l|}{2003} \\
\hline Urban & 36,101 & 43,434 & 10,588 & 90,123 & 42.7 & 46.2 & 11.1 & 41.4 \\
\hline Rural & 95,885 & 33,709 & 3,074 & 132,668 & 76.0 & 21.9 & 2.0 & 58.6 \\
\hline Total & 131,986 & 77,143 & 13,662 & 222,791 & 62.2 & 32.0 & 5.8 & 100.0 \\
\hline \multicolumn{9}{|l|}{2006} \\
\hline Urban & 38,072 & 47,973 & 12,193 & 98,238 & 41.1 & 46.7 & 12.2 & 43.3 \\
\hline Rural & 113,461 & 47,047 & 4,718 & 165,226 & 73.4 & 24.2 & 2.4 & 56.7 \\
\hline Total & 151,533 & 95,020 & 16,911 & 263,464 & 59.4 & 33.9 & 6.6 & 100.0 \\
\hline \multicolumn{9}{|l|}{2009} \\
\hline Urban & 36,013 & 47,416 & 14,036 & 97,465 & 40.3 & 46.3 & 13.4 & 49.0 \\
\hline Rural & 110,753 & 50,913 & 7,928 & 169,594 & 70.0 & 25.7 & 4.3 & 51.0 \\
\hline Total & 146,766 & 98,329 & 21,964 & 267,059 & 55.4 & 35.8 & 8.7 & 100.0 \\
\hline \multicolumn{9}{|l|}{2011} \\
\hline Urban & 43,304 & 53,520 & 16,573 & 113,397 & 39.9 & 46.6 & 13.5 & 49.9 \\
\hline Rural & 102,758 & 46,127 & 6,240 & 155,125 & 68.5 & 28.1 & 3.4 & 50.1 \\
\hline Total & 146,062 & 99,647 & 22,813 & 268,522 & 54.2 & 37.4 & 8.4 & 100.0 \\
\hline
\end{tabular}


Table 2

Mean Per Capita Expenditure by Educational Group and Mean Years of Education in Urban and Rural Sectors

\begin{tabular}{|c|c|c|c|c|c|}
\hline & \multicolumn{4}{|c|}{$\begin{array}{c}\text { Mean per capita Exp. } \\
\text { (in 1,000 Rp.) }\end{array}$} & \multirow[t]{2}{*}{$\begin{array}{r}\text { Mean Years o } \\
\text { Educatior } \\
\end{array}$} \\
\hline & Primary & Secondary & Tertiary & Total & \\
\hline \multicolumn{6}{|l|}{1997} \\
\hline Urban & 71.5 & 104.6 & 189.3 & 99.0 & 8.38 \\
\hline Rural & 48.6 & 63.2 & 95.4 & 52.2 & 5.05 \\
\hline Total & 54.0 & 86.8 & 168.5 & 68.8 & 6.23 \\
\hline U-R Ratio & 1.47 & 1.66 & 1.98 & 1.90 & 1.66 \\
\hline \multicolumn{6}{|l|}{2000} \\
\hline Urban & 139.7 & 191.0 & 309.3 & 180.2 & 8.33 \\
\hline Rural & 104.8 & 127.3 & 174.2 & 110.5 & 5.13 \\
\hline Total & 115.2 & 166.8 & 283.8 & 139.9 & 6.48 \\
\hline U-R Ratio & 1.33 & 1.50 & 1.78 & 1.63 & 1.62 \\
\hline \multicolumn{6}{|l|}{2003} \\
\hline Urban & 218.7 & 311.1 & 515.4 & 294.3 & 8.57 \\
\hline Rural & 162.8 & 197.2 & 274.6 & 172.6 & 5.49 \\
\hline Total & 178.7 & 265.4 & 465.7 & 223.0 & 6.77 \\
\hline U-R Ratio & 1.34 & 1.58 & 1.88 & 1.71 & 1.56 \\
\hline \multicolumn{6}{|l|}{2006} \\
\hline Urban & 307.0 & 443.7 & 775.6 & 428.0 & 8.79 \\
\hline Rural & 218.9 & 269.8 & 416.4 & 235.9 & 5.74 \\
\hline Total & 245.3 & 373.3 & 702.1 & 319.0 & 7.06 \\
\hline U-R Ratio & 1.40 & 1.64 & 1.86 & 1.81 & 1.53 \\
\hline \multicolumn{6}{|l|}{2009} \\
\hline Urban & 432.9 & 629.3 & $1,078.7$ & 610.3 & 8.89 \\
\hline Rural & 326.3 & 411.1 & 563.9 & 358.3 & 6.10 \\
\hline Total & 364.3 & 549.4 & 949.8 & 481.8 & 7.47 \\
\hline U-R Ratio & 1.33 & 1.53 & 1.91 & 1.70 & 1.46 \\
\hline \multicolumn{6}{|l|}{2011} \\
\hline Urban & 521.6 & 808.3 & $1,559.4$ & 795.5 & 9.18 \\
\hline Rural & 416.1 & 545.5 & 887.8 & 468.5 & 6.30 \\
\hline Total & 454.9 & 709.3 & $1,424.1$ & 631.8 & 7.73 \\
\hline U-R Ratio & 1.25 & 1.48 & 1.76 & 1.70 & 1.46 \\
\hline
\end{tabular}


Table 3

\section{Blinder-Oaxaca Decomposition of Urban-Rural Difference in Mean Per Capita Expenditure: Twofold Decomposition}

\begin{tabular}{|c|c|c|c|c|c|c|c|c|}
\hline & & Coef. & z-value & $\begin{array}{r}\text { Contrib. } \\
(\%)\end{array}$ & & Coef. & z-value & $\begin{array}{r}\text { Contrib. } \\
(\%)\end{array}$ \\
\hline & 1997 & & & & 2000 & & & \\
\hline \multicolumn{9}{|l|}{ Differential } \\
\hline Prediction for urban & & 11.254 & $4,954.5$ & & & 11.923 & $5,880.5$ & \\
\hline Prediction for rural & & 10.757 & $8,467.3$ & & & 11.523 & $8,705.5$ & \\
\hline Difference & & 0.497 & 191.1 & 100.0 & & 0.400 & 165.4 & 100.0 \\
\hline \multicolumn{9}{|l|}{ Explained part } \\
\hline Education year & & 0.168 & 123.2 & 33.7 & & 0.136 & 111.0 & 33.9 \\
\hline Age & & -0.010 & -11.3 & -2.0 & & -0.006 & -6.3 & -1.5 \\
\hline Age squared & & 0.006 & 9.4 & 1.1 & & 0.004 & 5.6 & 0.9 \\
\hline Household size & & -0.009 & -8.9 & -1.8 & & -0.012 & -11.7 & -3.0 \\
\hline Gender & & 0.001 & 8.2 & 0.1 & & 0.000 & 6.3 & 0.1 \\
\hline Total & & 0.155 & 96.1 & 31.2 & & 0.122 & 80.3 & 30.5 \\
\hline \multicolumn{9}{|l|}{ Unexplained part } \\
\hline \multirow[t]{2}{*}{ Total } & & 0.342 & 147.9 & 68.8 & & 0.278 & 127.9 & 69.5 \\
\hline & 2003 & & & & 2006 & & & \\
\hline \multicolumn{9}{|l|}{ Differential } \\
\hline Prediction for urban & & 12.404 & $6,652.7$ & & & 12.751 & $6,715.0$ & \\
\hline Prediction for rural & & 11.970 & $9,549.9$ & & & 12.280 & $10,000.0$ & \\
\hline Difference & & 0.434 & 193.2 & 100.0 & & 0.472 & 210.7 & 100.0 \\
\hline \multicolumn{9}{|l|}{ Explained part } \\
\hline Education year & & 0.138 & 121.0 & 31.8 & & 0.143 & 128.7 & 30.3 \\
\hline Age & & -0.009 & -9.3 & -2.0 & & -0.012 & -13.0 & -2.5 \\
\hline Age squared & & 0.006 & 8.1 & 1.3 & & 0.008 & 12.2 & 1.8 \\
\hline Household size & & -0.006 & -6.0 & -1.3 & & -0.006 & -6.4 & -1.2 \\
\hline Gender & & 0.000 & 0.8 & 0.0 & & 0.000 & 3.1 & 0.0 \\
\hline Total & & 0.130 & 92.8 & 29.9 & & 0.134 & 100.7 & 28.4 \\
\hline \multicolumn{9}{|l|}{ Unexplained part } \\
\hline \multirow[t]{2}{*}{ Total } & & 0.305 & 150.2 & 70.1 & & 0.338 & 169.3 & 71.6 \\
\hline & 2009 & & & & 2011 & & & \\
\hline \multicolumn{9}{|l|}{ Differential } \\
\hline Prediction for urban & & 13.161 & $6,890.2$ & & & 13.338 & $6,679.1$ & \\
\hline Prediction for rural & & 12.705 & $11,000.0$ & & & 12.921 & $8,858.1$ & \\
\hline Difference & & 0.456 & 202.5 & 100.0 & & 0.417 & 168.6 & 100.0 \\
\hline \multicolumn{9}{|l|}{ Explained part } \\
\hline Education year & & 0.137 & 124.9 & 29.9 & & 0.176 & 134.8 & 42.3 \\
\hline Age & & -0.013 & -13.9 & -2.7 & & -0.013 & -13.0 & -3.1 \\
\hline Age squared & & 0.010 & 13.4 & 2.2 & & 0.010 & 12.7 & 2.5 \\
\hline Household size & & 0.000 & 0.2 & 0.0 & & 0.004 & 5.1 & 1.0 \\
\hline Gender & & 0.000 & 6.7 & 0.1 & & 0.000 & 4.3 & 0.0 \\
\hline Total & & 0.135 & 104.8 & 29.5 & & 0.178 & 122.0 & 42.8 \\
\hline \multicolumn{9}{|l|}{ Unexplained part } \\
\hline Total & & 0.322 & 157.7 & 70.5 & & 0.239 & 107.6 & 57.2 \\
\hline
\end{tabular}


Table 4

Decomposition of Expenditure Inequality by Location and Educational Group in Each Location by Theil T Index

\begin{tabular}{|c|c|c|c|c|c|c|c|}
\hline & Inequality & Contrib. (\%) & Exp. Share (\%) & & Inequality & Contrib. (\%) & Exp. Share $(\%)$ \\
\hline \multicolumn{8}{|l|}{1997} \\
\hline Total & 0.260 & 100.0 & 100.0 & & & & \\
\hline B-sector (BS) & 0.051 & 19.5 & & & & & \\
\hline W-sector (WS) & 0.209 & 80.5 & & & & & \\
\hline Urban Sector & 0.280 & 55.1 & 51.2 & Rural Sector & 0.135 & 25.4 & 48.8 \\
\hline B-group & 0.055 & 10.7 & & B-group & 0.010 & 2.0 & \\
\hline W-group & 0.225 & 44.4 & & W-group & 0.124 & 23.4 & \\
\hline Primary & 0.180 & 11.4 & 16.4 & Primary & 0.113 & 15.8 & 36.3 \\
\hline Secondary & 0.207 & 19.4 & 24.4 & Secondary & 0.152 & 6.5 & 11.1 \\
\hline Tertiary & 0.339 & 13.6 & 10.4 & Tertiary & 0.180 & 1.0 & 1.5 \\
\hline \multicolumn{8}{|l|}{2000} \\
\hline Total & 0.200 & 100.0 & 100.0 & & & & \\
\hline B-sector (BS) & 0.030 & 14.9 & & & & & \\
\hline W-sector (WS) & 0.171 & 85.1 & & & & & \\
\hline Urban Sector & 0.220 & 59.7 & 54.4 & Rural Sector & 0.112 & 25.5 & 45.6 \\
\hline B-group & 0.035 & 9.6 & & B-group & 0.006 & 1.3 & \\
\hline W-group & 0.185 & 50.1 & & $\mathrm{~W}$-group & 0.106 & 24.2 & \\
\hline Primary & 0.148 & 14.1 & 19.1 & Primary & 0.101 & 17.1 & 33.9 \\
\hline Secondary & 0.195 & 24.7 & 25.4 & Secondary & 0.117 & 6.1 & 10.4 \\
\hline Tertiary & 0.230 & 11.2 & 9.8 & Tertiary & 0.156 & 1.0 & 1.3 \\
\hline \multicolumn{8}{|l|}{2003} \\
\hline Total & 0.216 & 100.0 & 100.0 & & & & \\
\hline B-sector (BS) & 0.035 & 16.4 & & & & & \\
\hline W-sector (WS) & 0.180 & 83.6 & & & & & \\
\hline Urban Sector & 0.229 & 58.1 & 54.7 & Rural Sector & 0.122 & 25.5 & 45.3 \\
\hline B-group & 0.042 & 10.6 & & B-group & 0.006 & 1.3 & \\
\hline W-group & 0.188 & 47.5 & & W-group & 0.115 & 24.2 & \\
\hline Primary & 0.151 & 12.1 & 17.4 & Primary & 0.106 & 16.0 & 32.5 \\
\hline Secondary & 0.184 & 22.8 & 26.7 & Secondary & 0.130 & 6.8 & 11.4 \\
\hline Tertiary & 0.257 & 12.6 & 10.6 & Tertiary & 0.194 & 1.3 & 1.5 \\
\hline \multicolumn{8}{|l|}{2006} \\
\hline Total & 0.248 & 100.0 & 100.0 & & & & \\
\hline B-sector (BS) & 0.044 & 17.7 & & & & & \\
\hline W-sector (WS) & 0.204 & 82.3 & & & & & \\
\hline Urban Sector & 0.251 & 58.7 & 58.1 & Rural Sector & 0.139 & 23.6 & 41.9 \\
\hline B-group & 0.051 & 11.9 & & B-group & 0.010 & 1.7 & \\
\hline $\mathrm{W}$-group & 0.200 & 46.8 & & W-group & 0.129 & 21.9 & \\
\hline Primary & 0.170 & 11.7 & 17.1 & Primary & 0.115 & 13.3 & 28.6 \\
\hline Secondary & 0.190 & 21.5 & 28.1 & Secondary & 0.154 & 7.2 & 11.6 \\
\hline Tertiary & 0.263 & 13.6 & 12.9 & Tertiary & 0.197 & 1.4 & 1.8 \\
\hline \multicolumn{8}{|l|}{2009} \\
\hline Total & 0.238 & 100.0 & 100.0 & & & & \\
\hline B-sector (BS) & 0.034 & 14.5 & & & & & \\
\hline W-sector (WS) & 0.203 & 85.5 & & & & & \\
\hline Urban Sector & 0.240 & 62.7 & 62.1 & Rural Sector & 0.143 & 22.8 & 37.9 \\
\hline B-group & 0.051 & 13.4 & & B-group & 0.012 & 1.8 & \\
\hline W-group & 0.189 & 49.3 & & W-group & 0.132 & 21.0 & \\
\hline Primary & 0.160 & 12.0 & 17.8 & Primary & 0.116 & 11.8 & 24.1 \\
\hline Secondary & 0.191 & 23.8 & 29.7 & Secondary & 0.148 & 7.0 & 11.2 \\
\hline Tertiary & 0.218 & 13.5 & 14.7 & Tertiary & 0.203 & 2.2 & 2.6 \\
\hline \multicolumn{8}{|l|}{2011} \\
\hline Total & 0.322 & 100.0 & 100.0 & & & & \\
\hline B-sector (BS) & 0.034 & 10.5 & & & & & \\
\hline W-sector (WS) & 0.288 & 89.5 & & & & & \\
\hline Urban Sector & 0.330 & 64.5 & 62.9 & Rural Sector & 0.217 & 25.0 & 37.1 \\
\hline B-group & 0.076 & 14.8 & & B-group & 0.019 & 2.2 & \\
\hline W-group & 0.255 & 49.7 & & W-group & 0.198 & 22.8 & \\
\hline Primary & 0.232 & 11.8 & 16.4 & Primary & 0.183 & 12.9 & 22.6 \\
\hline Secondary & 0.241 & 22.3 & 29.8 & Secondary & 0.216 & 8.2 & 12.2 \\
\hline Tertiary & 0.301 & 15.6 & 16.6 & Tertiary & 0.242 & 1.8 & 2.4 \\
\hline
\end{tabular}

(Note) Sectors 1 and 2 refer to urban and rural sectors. 
Table 5

Hierarchical vs. Non-hierarchical Decomposition of Expenditure Inequality by Theil T: Location $\Rightarrow$ Education

\begin{tabular}{|c|c|c|c|c|}
\hline & \multicolumn{2}{|c|}{ Hierarchical Decomposition } & \multicolumn{2}{|c|}{ Non-hierarchical Decomposition } \\
\hline & Inequality & Contribution $(\%)$ & Inequality & Contribution (\%) \\
\hline \multicolumn{5}{|l|}{1997} \\
\hline Total & 0.260 & 100.0 & 0.260 & 100.0 \\
\hline B-sector (BS) & 0.051 & 19.5 & 0.051 & 19.5 \\
\hline B-group (BG) & & & 0.062 & 23.8 \\
\hline Interaction Term (ISG) & & & -0.029 & -11.1 \\
\hline W-sector B-group (WSBG) & 0.033 & 12.7 & & \\
\hline W-sector W-group (WSWG) & 0.176 & 67.8 & 0.176 & 67.8 \\
\hline \multicolumn{5}{|l|}{2000} \\
\hline Total & 0.200 & 100.0 & 0.200 & 100.0 \\
\hline B-sector (BS) & 0.030 & 14.9 & 0.030 & 14.9 \\
\hline B-group (BG) & & & 0.038 & 19.0 \\
\hline Interaction Term (ISG) & & & -0.016 & -8.2 \\
\hline W-sector B-group (WSBG) & 0.022 & 10.9 & & \\
\hline W-sector W-group (WSWG) & 0.149 & 74.3 & 0.149 & 74.3 \\
\hline \multicolumn{5}{|l|}{2003} \\
\hline Total & 0.216 & 100.0 & 0.216 & 100.0 \\
\hline B-sector (BS) & 0.035 & 16.4 & 0.035 & 16.4 \\
\hline B-group (BG) & & & 0.045 & 20.7 \\
\hline Interaction Term (ISG) & & & -0.019 & -8.8 \\
\hline W-sector B-group (WSBG) & 0.026 & 11.9 & & \\
\hline W-sector W-group (WSWG) & 0.155 & 71.7 & 0.155 & 71.7 \\
\hline \multicolumn{5}{|l|}{2006} \\
\hline Total & 0.248 & 100.0 & 0.248 & 100.0 \\
\hline B-sector (BS) & 0.044 & 17.7 & 0.044 & 17.7 \\
\hline B-group (BG) & & & 0.057 & 23.2 \\
\hline Interaction Term (ISG) & & & -0.024 & -9.5 \\
\hline W-sector B-group (WSBG) & 0.034 & 13.6 & & \\
\hline W-sector W-group (WSWG) & 0.171 & 68.7 & 0.171 & 68.7 \\
\hline \multicolumn{5}{|l|}{2009} \\
\hline Total & 0.238 & 100.0 & 0.238 & 100.0 \\
\hline B-sector (BS) & 0.034 & 14.5 & 0.034 & 14.5 \\
\hline B-group (BG) & & & 0.053 & 22.5 \\
\hline Interaction Term (ISG) & & & -0.017 & -7.3 \\
\hline W-sector B-group (WSBG) & 0.036 & 15.2 & & \\
\hline W-sector W-group (WSWG) & 0.167 & 70.3 & 0.167 & 70.3 \\
\hline \multicolumn{5}{|l|}{2011} \\
\hline Total & 0.322 & 100.0 & 0.322 & 100.0 \\
\hline B-sector (BS) & 0.034 & 10.5 & 0.034 & 10.5 \\
\hline B-group (BG) & & & 0.075 & 23.3 \\
\hline Interaction Term (ISG) & & & -0.021 & -6.4 \\
\hline W-sector B-group (WSBG) & 0.054 & 16.9 & & \\
\hline W-sector W-group (WSWG) & 0.233 & 72.6 & 0.233 & 72.6 \\
\hline
\end{tabular}

(Note) Sectors 1 and 2 refer to urban and rural sectors. 
Table 6

Distribution of Households according to Occupations in Each Educational Group in

2011

\begin{tabular}{|c|c|c|c|c|c|c|c|c|c|c|c|}
\hline & \multicolumn{5}{|c|}{ Urban Sector } & \multicolumn{5}{|c|}{ Rural Sector } & \multirow[b]{2}{*}{$\begin{array}{r}\text { GDP } \\
\text { Growth } \\
\text { Rate } \\
2000-11 \\
(\%)\end{array}$} \\
\hline & $\begin{array}{r}\text { Mean } \\
\text { PCE } \\
(1,000 \\
\text { Rp. })\end{array}$ & $\begin{array}{r}\text { Primary } \\
(\%)\end{array}$ & $\begin{array}{r}\text { Second. } \\
(\%)\end{array}$ & $\begin{array}{r}\text { Tertiary } \\
(\%)\end{array}$ & $\begin{array}{r}\text { Total } \\
(\%)\end{array}$ & $\begin{array}{r}\text { Mean } \\
\text { PCE } \\
(1,000 \\
\text { Rp. })\end{array}$ & $\begin{array}{r}\text { Primary } \\
(\%)\end{array}$ & $\begin{array}{r}\text { Second. } \\
(\%)\end{array}$ & $\begin{array}{r}\text { Tertiary } \\
(\%)\end{array}$ & $\begin{array}{r}\text { Total } \\
(\%)\end{array}$ & \\
\hline Agriculture & 476 & 28.3 & 7.5 & 3.1 & 14.8 & 421 & 67.5 & 47.3 & 13.5 & 59.7 & 3.5 \\
\hline Mining/Quarrying & 1,004 & 1.2 & 1.6 & 1.5 & 1.4 & 552 & 1.9 & 2.4 & 0.8 & 2.0 & 1.1 \\
\hline Manufacturing & 785 & 11.2 & 18.5 & 8.7 & 14.4 & 471 & 6.1 & 8.1 & 2.8 & 6.6 & 4.6 \\
\hline Electricity/Gas/Water & 1,098 & 0.1 & 0.9 & 1.0 & 0.6 & 592 & 0.1 & 0.3 & 0.3 & 0.2 & 7.7 \\
\hline Construction & 633 & 11.9 & 9.2 & 5.2 & 9.7 & 432 & 6.9 & 8.1 & 1.5 & 7.1 & 6.9 \\
\hline Trade/Hotel/Restaurant & 836 & 24.3 & 27.0 & 17.2 & 24.7 & 566 & 9.6 & 13.6 & 8.4 & 10.7 & 6.3 \\
\hline Transportation & 663 & 8.7 & 9.3 & 3.2 & 8.3 & 519 & 3.0 & 6.2 & 1.8 & 3.9 & 6.3 \\
\hline Information & 1,446 & 0.1 & 0.8 & 2.6 & 0.7 & 705 & 0.0 & 0.1 & 0.4 & 0.1 & 21.1 \\
\hline Finance/Real Estate & 1,315 & 0.2 & 1.6 & 5.8 & 1.6 & 832 & 0.0 & 0.5 & 1.5 & 0.2 & 6.7 \\
\hline Education Services & 1,079 & 0.3 & 1.6 & 18.2 & 3.3 & 780 & 0.1 & 1.6 & 40.6 & 2.0 & \\
\hline Health Services & 1,282 & 0.3 & 0.8 & 3.2 & 0.9 & 879 & 0.1 & 0.4 & 3.5 & 0.3 & 5.5 \\
\hline Government Services & 904 & 12.1 & 20.0 & 29.5 & 18.2 & 591 & 3.9 & 10.5 & 24.5 & 6.5 & \\
\hline Others & 881 & 1.5 & 1.3 & 0.8 & 1.3 & 445 & 0.7 & 0.8 & 0.5 & 0.7 & \\
\hline Total & 782 & 100.0 & 100.0 & 100.0 & 100.0 & 468 & 100.0 & 100.0 & 100.0 & 100.0 & 5.3 \\
\hline
\end{tabular}


Table 7

Decomposition of Inequality within Urban Sector's Tertiary Education Group by Education Subgroup in 2000 and 2011

\begin{tabular}{lrrrr}
\hline & Inequality & $\begin{array}{r}\text { Contribution } \\
(\%)\end{array}$ & $\begin{array}{r}\text { Expenditure } \\
\text { Share } \\
(\%)\end{array}$ & $\begin{array}{r}\text { Mean Per } \\
\text { Capita Exp. } \\
(1,000 \text { Rp. })\end{array}$ \\
\hline 2000 & & & & \\
Urban Sector's Tertiary Group & 0.230 & 100.0 & 100.0 & 309 \\
$\quad$ B-subgroup & 0.007 & 2.8 & & \\
W-subgroup & 0.223 & 97.2 & & \\
D1, 2 \& 3 & 0.231 & 28.8 & 28.6 & 272 \\
D4 \& S1 & 0.216 & 62.4 & 66.4 & 321 \\
$\quad$ S2 \& 3 & 0.279 & 6.0 & 5.0 & \\
\hline 2011 Srator's Tertiary Group & & & & \\
Urban Sector & 0.300 & 100.0 & 100.0 & 1,559 \\
B-subgroup & 0.006 & 1.9 & & \\
W-subgroup & 0.294 & 98.1 & & \\
Diploma 1, 2 \& 3 & 0.403 & 29.0 & 21.6 & 1,409 \\
Diploma 4 \& Sarjana 1 & 0.260 & 58.2 & 67.0 & 1,560 \\
Sarjana 2 \& 3 & 0.287 & 10.9 & 11.4 & 2,060 \\
\hline
\end{tabular}

(Note) Sarjana 1, 2 and 3 are, respectively, Bachelor degree, Master's degree and Doctoral degree. 